\title{
EL DAÑO MORAL DE LOS DUEÑOS POR ATAQUES EN SUS MASCOTAS
}

\author{
THE MORAL DAMAGE OF OWNERS FROM ATTACKS ON \\ THEIR PETS.
}

DAVID ALEJANDRO RODRÍGUEZ GUERRA*

\section{Resumen}

Las normas jurídicas que regulan a las mascotas y animales de compañía se encuentran en el Código Civil, en la ley sobre protección animal y en la ley de tenencia responsable de mascotas y animales de compañía. De acuerdo a esta última, para que una mascota sea tal, debe cumplir la finalidad de acompañar y dar seguridad a su dueño. De dichas finalidades se deriva que las mascotas pueden ser considerados bienes con valor de afección para él. Sin embargo, estas características no modifican su régimen jurídico, de manera que seguirían siendo bienes, por ello, no pueden sufrir daño moral. Quien sufriría un daño moral sería siempre su dueño, ya que las mascotas formarían parte del patrimonio de este último.

\section{Palabras clave}

Mascotas, bienes, valor de afección, daño moral.

\begin{abstract}
The legal regulations that rule pets and companion animals are found in the Civil Code, in the animal protection law and in the responsible pet and companion animal's holding law. According to the latter, for a pet to be such, it must fulfill the purpose of accompanying and providing security
\end{abstract}


to its owner. From such purposes it is derived that pets can be considered goods with a value of affection for him. However, these characteristics do not change their legal status, so they would still be goods, that means that they cannot suffer moral damage. The person who would suffer moral damage would always be the owner, since pets would be part of the owner's patrimony.

\section{Keywords}

Pets, goods, value of affection, moral damage.

\section{INTRODUCCIÓN}

Las mascotas se han transformado en seres bien apreciados por los humanos, y aquello se ha intensificado en el último tiempo. No son pocos los que aman a sus mascotas más que a cualquier cosa y tampoco son pocos los que los consideran miembros de sus respectivas familias, es decir, miembros no humanos de la familia'.

Lo anterior no debiera resultar extraño toda vez que la característica fundamental de una mascota es que provee compañía y seguridad a los humanos, de manera tal que son cosas que con el tiempo han logrado posicionarse como bienes con alta valoración social ${ }^{2}$, al menos, más alta que cualquier otra cosa.

El presente trabajo tiene por objeto estudiar si esta alta valoración social de la que gozan las mascotas puede traducirse en que si un ataque en ellos produce un daño moral indemnizable para su dueño.

Artículo recibido para su evaluación el 10 de mayo de 2020, y aprobado para su publicación el 20 de julio de 2020.

* Abogado, Licenciado en Ciencias Jurídicas y Sociales y Magíster en Derecho Civil Patrimonial Universidad Diego Portales. Santiago de Chile. Email: David.rodriguezg@, mail.udp.cl.

1 DÍAZ VIDELA, Marcos: "El miembro no humano de la familia: las mascotas a través del ciclo vital familiar”. En: Revista Ciencia Animal, No 9, 2015. pp. 83-98.

2 Cabe destacar que esta alta valoración social no tan solo proviene de la compañía y seguridad, sino que de otras actividades que involucran animales y mascotas, como el uso terapéutico. Ver más en JOFRÉ M, Leonor: "Visita terapéutica de mascotas en hospitales”. En: Revista Chilena de Infectología, Vol. 22, 2005. pp. 257-262; LÓPEZ, J, PEÑA, A, ABARCA, K: "Tenencia de mascotas en pacientes inmunocomprometidos: actualización y consideraciones veterinarias y médicas". En: Revista Chilena de Infectología, Vol. 30, ํ3, 2013. pp. 52-62. 
Para cumplir con dicho objetivo se analizará el régimen jurídico de animales y mascotas, exponiendo su tratamiento normativo en el Código Civil, en la Ley $\mathrm{N}^{\circ} 20.380$ sobre protección de animales y en la Ley $\mathrm{N}^{\circ}$ 21.020 sobre tenencia responsable de mascotas y animales de compañía; se estudiará si son cosas con contenido pecuniario o económico estricto o si por el contrario son bienes con valor de afección; y finalmente, se estudiará si las mascotas pueden reclamar un daño moral propio o si, por el contrario, siempre es el dueño la víctima directa del daño. Para analizar todo estos puntos, se tomará como base de análisis un fallo dictado por un Ministro de Fuero de la Corte de Apelaciones de Santiago que se pasará a exponer a continuación.

\section{ANTECEDENTES DE UN CASO}

Un Ministro de Fuero de la Corte de Apelaciones de Santiago ${ }^{3}$, conoció en primera instancia de la demanda civil de indemnización de perjuicios deducida por la demandante, la cual se fundó en que, con fecha 23 de junio se encontraba paseando a su perra de raza Schnauzer llamada "Olivia" de seis años de edad, junto con un acompañante, en las calles Gertrudis Echeñique con Renato Sánchez, en el barrio El Golf, cuando durante su paseo, la perra de la demandada, que es de la misma raza pero de tamaño mediano y por consiguiente más agresiva, corrió aceleradamente directo hacia ellos mordiendo fuertemente a Olivia, hiriéndola gravemente en una de sus patas traseras. Alega que la perra estaba con arnés y correa pero sin que su dueña estuviese controlándola, quien al llegar dijo "habérsele soltado". La demandante indica que su acompañante tuvo que levantar en sus brazos a Olivia, ya que de no haberlo hecho, la perra de la demandada la habría matado. Hace presente que Olivia es una mascota que vive en un departamento, por lo que carece de habilidades necesarias para poder enfrentarse en una pelea frente a otros perros. Atendidos los hechos relatados, la demandante exige el pago de los perjuicios causados contemplando el daño emergente correspondiente a los gastos veterinarios y el daño moral avaluado en un millón de pesos. Para puntualizar lo anterior, pide tener presente que el hecho de que una mascota que los ha acompañado durante más de seis años sea brutalmente atacada por un animal fiero, es un hecho traumático, al punto que ha ocasionado en la mascota un episodio de afectación general, pero, además, una afectación

3 Vivanco con Nazal (Corte de Apelaciones de Santiago, 09 de septiembre de 2019, Rol $\mathrm{N}^{\circ}$ 13-2018). 
en el núcleo familiar de sus dueños, en el entendido que se encuentran limitados en la actualidad para pasearla (tiene pánico de salir a la calle y sociabilizar con otros animales), y por presentar problemas conductuales derivados del ataque.

La demandada contestó la demanda, indicando que, en lo esencial, efectivamente su perra mordió a la perra de la demandante y le causó una herida en una de sus patas. Expone que con fecha 23 de junio de 2018 sacó a pasear a su perra llamada "Mica", una Schnauzer de mediano porte, y se detuvo a conversar con una conocida en la esquina de Gertrudis Echeñique con Renato Sánchez, teniendo a su perra sujeta de la correa. De improviso su perra se desató violentamente de su mano, cruzando en forma oblicua a la calle y se lanzó contra la perra de la demandante sin que pudiera evitarlo. Pese a sus disculpas, la demandante estaba muy alterada y no le permitió mayor diálogo. Indica que tiene el propósito de pagar los daños causados por la responsabilidad que pudiere caberle por los hechos ocurridos, sin embargo, discrepa absolutamente del monto reclamado a título de daño moral, de manera que fijó dicha indemnización en un monto no superior a cien mil pesos.

El Ministro de Fuero acogió la demanda en todas sus partes. Declaró que es un hecho no controvertido que el día 23 de junio de 2018, mientras la demandante paseaba a su perra de raza Schnauzer en las calles Gertrudis Echeñique con Renato Sánchez, una perra de su misma raza propiedad de la demandada, corrió a hacia su perra logrando morderla causándole una herida en una pierna. Junto con aquello, el Ministro trajo a la vista copia autorizada del expediente Rol 15-347-2018 del Segundo Juzgado de Policía Local de Las Condes en la que se conoció la parte infraccional de los hechos que motivaron la demanda, en la que con fecha 31 de enero de 2019, se dictó sentencia por la que se acogió la denuncia infraccional y se condenó a la demandada al pago de una multa de 20 Unidades Tributarias Mensuales por la infracción al artículo 10 de la ley 21.020 al no dar cumplimiento a la Ordenanza Municipal de Las Condes sobre Tenencia Responsable de Mascotas y Animales de Compañía en su artículo $15 \mathrm{~N}^{\circ} 9$, por mantener suelta a su mascota en la vía pública. Así mismo recurrió al artículo 13 de la referida ley, el que establece que "Todo responsable de un animal regulado en esta ley responderá siempre civilmente de los daños que se causen por acción del animal, sin perjuicio de la responsabilidad penal que le corresponda", resultando plenamente aplicable el inciso primero del artículo 2326 del Código Civil. 
De los dichos de tres testigos legalmente interrogados, sin tachas y contestes, se tuvo por acreditado que Olivia es una perrita inserta en un grupo familiar humano, como una mascota querida, tratada no como una cosa sino como un miembro importante del entorno familiar, bien cuidada en cuanto se facilitan frecuentes paseos y de aspecto alegre, lo que cambió luego del ataque.

En virtud de lo anterior y considerando que la demandada reconoció que su perra se le soltó y atacó a la perra de la demandante y mostrándose dispuesta a pagar los daños causados por la responsabilidad que pudiera caberle, el Ministro tuvo por acreditado que la demandada fue negligente en el cuidado de su animal, permitiendo en forma culposa que aquel mordiere y causare lesiones a la mascota de la demandante.

En cuanto al daño emergente, la demandada no controvirtió el monto, de manera que el Ministro de Fuero agregó a los hechos no controvertidos que el daño emergente producto de la atención y curaciones a Olivia asciende a $\$ 56.500$ y se acogió dicha pretensión. En cuanto al daño moral, el Ministro consideró que dada la intensidad del afecto y haber sentido los días posteriores una intensa aflicción psicológica que se tradujo en una inseguridad para hacer nuevamente con ella cosas cotidianas como darle paseos, acogió dicha pretensión, avaluando discrecionalmente su monto en un millón de pesos.

\section{EL RÉGIMEN JURÍDICO DE LOS ANIMALES Y MASCOTAS}

Para poder analizar correctamente la indemnización del daño moral del dueño por ataques a su mascota, primero debe despejarse el régimen jurídico de estos. La legislación nacional contempla normas que hacen referencia a la definición de los animales y mascotas. En torno a ellos podría decirse que existe una dispersión normativa. Esta dispersión implica la revisión de, a lo menos, tres cuerpos normativos. Por una parte los animales se encuentran regulados en el Código Civil (en adelante "el Código"); por otra parte, en la Ley sobre protección de animales; y finalmente en la Ley sobre tenencia de responsables de mascotas y animales de compañía.

En lo que respecta al Código, el artículo 566 expresa que "Las cosas corporales se dividen en muebles e inmuebles". El artículo siguiente manifiesta que "Muebles son las que pueden transportarse de un lugar a otro, sea moviéndose ellas a sí mismas, como los animales (que por eso se llaman semovientes), sea que sólo se muevan por una fuerza externa, 
como las cosas inanimadas. Exceptúanse las que siendo muebles por naturaleza se reputan inmuebles por su destino, según el artículo 570”. Esta última norma establece en su inciso primero que "Se reputan inmuebles, aunque por naturaleza no lo sean, las cosas que están permanentemente destinadas al uso, cultivo y beneficio de un inmueble, sin embargo de que puedan separarse sin detrimento", y en su inciso final establece que son inmuebles por destinación "Los animales que se guardan en conejeras, pajareras, estanques, colmenas, y cualesquiera otros vivares, con tal que éstos adhieran al suelo, o sean parte del suelo mismo, o de un edificio".

Por lo tanto, de las normas citadas se infiere claramente que para la legislación nacional los animales son cosas, ya sea muebles semovientes o inmuebles por destinación, si están destinados al uso, cultivo o beneficio de un predio. Lo relevante es quedarnos con el concepto de cosa.

El Código, a su vez, clasificó y distinguió entre distintos tipos de animales y los agrupó en tres categorías. Estas categorías se encuentran desarrolladas en el artículo 608, norma que se refiere a la forma de adquirir ocupación. El artículo 608 expresa que "Se llaman animales bravíos o salvajes los que viven naturalmente libres e independientes del hombre, como las fieras y los peces; domésticos los que pertenecen a especies que viven ordinariamente bajo la dependencia del hombre, como las gallinas, las ovejas; y domesticados los que sin embargo de ser bravíos por su naturaleza se han acostumbrado a la domesticidad y reconocen en cierto modo el imperio del hombre".

De las normas antes transcritas parece inferirse que tan solo los animales domésticos o domesticados pueden ser inmuebles por destinación, mientras que los bravíos o salvajes siempre serán muebles semovientes. Aquello porque, por definición, los animales salvajes viven independientes del hombre, por lo que difícilmente podrán servir al uso, cultivo o beneficio de un predio. En caso de que el animal salvaje efectivamente sea usado con esa finalidad, lo convertirá, por definición, en un animal domesticado. Con todo, que un animal salvaje por naturaleza sea domesticado, no implica que este, por ese solo hecho, sirva de beneficio al predio. El artículo 2327 es claro en expresar la posibilidad de que un animal fiero pueda no servir a un predio. Este último artículo, junto con el 2326 del Código Civil, aparecen a propósito de la responsabilidad aquiliana o extracontractual. En específico, aparecen como una de las tres formas tradicionales de clasificación de las 
presunciones de culpa, es decir, son normas que regulan la presunción de culpa por el hecho de las cosas 4 .

De manera tal que todas las normas del Código parecen apuntar a que los animales, cualquiera sea su clasificación y naturaleza, son cosas.

Sin embargo, como se dijo anteriormente, el Código Civil no es el único cuerpo normativo que se refiere a los animales. Se han dictado dos leyes cuya finalidad precisa fue regular a estas cosas. Estas leyes son la Ley $\mathrm{N}^{\circ}$ 20.380 sobre protección de animales y la más reciente Ley $\mathrm{N}^{\circ} 21.020$ sobre tenencia responsable de mascotas y animales de compañía.

En la Ley sobre protección de animales, en su artículo $1^{\circ}$ se expresa que "Esta Ley establece normas destinadas a conocer, proteger y respetar a los animales, como seres vivos y parte de la naturaleza, con el fin de darles un trato adecuado y evitarles sufrimientos innecesarios". Esta Ley no modifica al Código Civil, de manera tal que los animales siguen siendo cosas y se siguen sometiendo a las clasificaciones ya expresadas. Si bien no cambia su estatus jurídico, de acuerdo a la Ley, los animales ya no son meramente cosas que pueden moverse solas, sino que son seres vivos que forman parte de la naturaleza, los cuales merecen un trato adecuado y sobre los que cabe evitar provocarles sufrimientos innecesarios. Por tanto, existe un reconocimiento legal expreso a que los animales son cosas vivas que pueden sufrir.

Por su parte, la Ley sobre tenencia responsable de mascotas y animales de compañía contempla, en su artículo $2^{\circ}$, una norma definitoria de la que se extraen diez definiciones. De tal manera, el artículo $2^{\circ}$ número $1^{\circ}$ expresa que "Para efectos de esta ley, se entenderá por: 1) Mascotas o animales de compañía: aquellos animales domésticos, cualquiera sea su especie, que sean mantenidos por las personas para fines de compañía o seguridad. Se excluyen aquellos animales cuya tenencia se encuentre regulada por leyes especiales".

Varias cosas cabe inferir de esto. Primero, solo los animales domésticos pueden ser mascotas. No los salvajes. No los domesticados. Por tanto, en conformidad al artículo 608 del Código, solo son mascotas los animales que viven ordinariamente bajo el imperio del hombre, como ovejas y gallinas y que no sean bravíos por naturaleza. Segundo, la calificación de mascota está supeditada a una finalidad, acompañar o dar seguridad al humano que

4 CORRAL TALCIANI, Hernán: Lecciones de responsabilidad civil extracontractual. $2^{\mathrm{a} e d . ~ A c t u a l i z a d a . ~ E d i t o r i a l ~ L e g a l ~ P u b l i s h i n g, ~ S a n t i a g o, ~ 2013 . ~ p p . ~ 245-246 . ~}$ 
ejerce imperio sobre ellos. Por tanto, un animal doméstico que no provee compañía ni seguridad, no es una mascota. Tercero, todas las mascotas son animales, pero no todos los animales son mascotas. Existe por tanto, una relación género - especie entre animales y mascotas, de forma tal, que las mascotas son una especie de animal. Cuarto, las mascotas, al ser animales, son seres vivos que forman parte de la naturaleza y merecen un trato adecuado y debe evitarse provocarles sufrimientos innecesarios. Quinto y final, las mascotas, al ser animales, son cosas. Sin embargo, su finalidad no es prestar servicio al predio, sino, dar compañía y seguridad al humano, por ende, es una cosa mueble semoviente. No inmueble por destinación. Cabe destacar, sin embargo, que dudas pueden existir en torno a mascotas que cumplan ambas funciones, acompañar y servir al predio. En mi parecer, dicho dilema se resuelve en virtud del principio de especialidad's La Ley sobre tenencia responsable de mascotas y animales de compañía es una norma especial en contraste con el Código, que es la general. En virtud de aquello, si un animal sirve al predio pero al mismo tiempo, acompaña y protege a su dueño, es un animal especial, en el sentido de que es un animal especializado en acompañar y proteger, y es aquella especialidad la que debe tomarse en cuenta al momento de clasificarlo como mueble o inmueble. Esto porque será un animal que de forma general sirve al predio, pero de forma especial acompaña y protege. De manera tal, que en mi parecer, al ser un animal especializado, debe ser clasificado en virtud de aquello que lo hace especial, por tanto, debe ser considerado mueble semoviente. En otros términos, su especialidad deroga su generalidad'.

5 Si un animal tiene la función de acompañar y proteger a su dueño y a la vez sirve al predio, nos encontramos con una inconsistencia de normas, ya que dos de ellas imputan al mismo caso soluciones incompatibles. En este caso el Código Civil y la Ley de tenencia responsable de mascotas son incompatibles, ya que para el Código la mascota sería un inmueble por destinación y para la Ley de tenencia responsable sería un mueble semoviente. De acuerdo a Carlos Nino citando a Alf Ross, esta sería una inconsistencia total-parcial, puesto que existen animales domésticos que solo sirven al predio, por ende no serían mascotas y serían inmuebles por destinación; existen animales domésticos que no sirven al predio y solo dan compañía y seguridad, por ende serían mascotas muebles semovientes; finalmente existen animales domésticos que sirven al predio y proveen compañía y seguridad, y es en este caso existe una incompatibilidad normativa. Carlos Nino manifiesta que "El principio lex specialis prescribe que se dé preferencia a la norma específica que está en conflicto con una cuyo campo de referencia sea más general" en NINO, Carlos Santiago: Introducción al análisis del derecho. $2^{\mathrm{a}}$ ed. Ampliada y revisada. Editorial Astrea de Alfredo y Ricardo Depalma, Buenos Aires, 2003. pp. 274275.

6 Al respecto Norberto Bobbio manifiesta que el criterio de resolución de antinomias lex specialis "es aquel con base en el cual de dos normas incompatibles, la una general y la 
Junto con el concepto de cosa, se encuentra el concepto de bien. Ya sabemos que las mascotas son cosas pero ¿son bienes? Se ha dicho que "entre las cosas y los bienes existe una relación de género a especie; bienes son las cosas que prestando una utilidad para el hombre, son susceptibles de apropiación; también se ha exigido que estén apropiadas"'. Respecto de la utilidad, Peñailillo ha manifestado que "si se asimila a la valoración económica, según se ha visto, es exigida por algunos ya en la cosa; dicha utilidad también presenta características de subjetividad y de relatividad que sería necesario determinar en cada caso concreto"s. De las normas del Código, es posible inferir que los animales pueden prestar una utilidad económica al hombre si estos son domésticos o domesticados, ya que estarían bajo el imperio del hombre y este podría sacarles utilidad económica. Por ejemplo si un animal doméstico se destina al uso del predio o uno salvaje domesticado se utiliza en un circo. De tal manera que si la utilidad es eminentemente económica, los animales bravíos o salvajes que existen libres e independientes, serían considerados cosas y no bienes. Misma conclusión se le aplicaría a las mascotas. Como se ha expuesto, la utilidad de las mascotas radica en su capacidad de proveer compañía o seguridad, lo que no tiene una utilidad económica, al menos no directa. Allí tendrá relevancia lo manifestado por Peñailillo, en cuanto a la utilidad subjetiva en cada caso concreto. Si esa utilidad puede subjetivarse, entonces los animales salvajes y las mascotas, pese a no tener una utilidad económica para el hombre, si pueden tener una utilidad subjetiva. Con todo, hay quienes niegan que la utilidad sea un requisito estricto para considerar que una cosa es un bien, y bastaría con el requisito de que la cosa sea susceptible de apropiación".

En lo que respecta a este último requisito, el de la apropiación, Peñailillo estima que "en ella influye la naturaleza de ciertas entidades como aprehensibles o no por el ser humano y la capacidad de aprehensión de éste" 10 , por su parte Troncoso Larronde manifiesta que "no toda cosa es

otra especial (o excepcional), prevalece la segunda: lex specialis derogat generali" en BOBBIO, Norberto: Teoría general del derecho. $2^{\mathrm{a} e d . ~ E d i t o r i a l ~ T e m i s, ~ B o g o t a ́, ~} 2002$. pp. 191-195.

7 PEÑAILILLO ARÉVALO, Daniel: Los bienes. La propiedad y otros derechos reales. $1^{\text {a }}$ ed. Editorial Jurídica de Chile, Santiago, 2006. pp. 15-16.

8 Ídem.

9 ALESSANDRI RODRÍGUEZ, Arturo: De los bienes. Editorial Zamorano y Caperan, Santiago, 1937. Pág. 5. TRONCOSO LARRONDE, Hernán: De los bienes. Editorial Thomson Reuters, Santiago, 2013. p. 1.

10 PEÑAILILLO, cit. p. 16. 
un bien, sino sólo aquellas susceptibles de apropiación, de dominio" Alessandri expresa que "Bienes son las cosas en cuanto son susceptibles de apropiación por los particulares; de manera que lo que caracteriza en su esencia a los bienes, es la circunstancia de poder ser objeto de propiedad privada, y no como creen algunos el hecho de que produzcan utilidades"12, zanjando el debate, negando el requisito de la utilidad y fijando el requisito de la apropiación como cumplido si puede ejercerse el dominio sobre la cosa de que trata.

Desde ese punto de vista, todos los animales, cualquiera sea su clasificación son bienes, y por ende, también las mascotas lo son, puesto que todos ellos son apropiables y aprehensibles. La distinción entre animales bravíos, domésticos y domesticados se encuentra en el artículo 608 del Código, a propósito de la ocupación, el cual es un modo de adquirir el dominio. El artículo 607 del Código expresa que "la caza y pesca son especies de ocupación por las cuales se adquiere el dominio de los animales bravíos" y el artículo 623 inciso $1^{\circ}$ manifiesta que "Los animales domésticos están sujetos a dominio", por tanto, no cabe duda alguna que en nuestra legislación los animales bravíos y domésticos pueden ser apropiables, y se debe recordar que los domesticados son bravíos que reconocen cierto imperio del hombre, al ser bravíos por naturaleza, entonces son apropiables por caza o pesca. Los artículos 2326 y 2327 del Código son normas que regulan la presunción de culpa del dueño de un animal por los hechos de este $^{13}$. Si los animales no pudieren ser apropiables, estas normas carecerían de todo sentido, primero porque hablan del "dueño" del animal, y aquello solo es posible si existe dominio sobre ellos, y segundo, porque no tendría sentido presumir la culpa de un humano por el hecho de un animal que no es de su propiedad.

Si bien es cierto que, de acuerdo a lo expresado anteriormente, el régimen jurídico de los animales, mascotas y animales de compañía corresponde al de cosas y bienes, corresponde hacer hincapié en el hecho

11 TRONCOSO, cit. p. 1.

12 ALESSANDRI, cit. p. 5.

13 Se ha distinguido entre "Presunción de culpa por el hecho ajeno (artículos 2320 a 2322 C.C); presunción de culpa por la ruina de un edificio (art. 2320 C.C.); presunción de culpa por un animal de que se es dueño (art. 2326 y 2327 C.C.) y presunción por las cosas que se caen o arrojan de la parte superior de un edificio (art. 2328 C.C.)" en SCHIELE, C, TOCORNAL, J: "Artículo 2329 del Código Civil. La interpretación de presunción por hechos propios existe en la jurisprudencia". En: Revista Chilena de Derecho, Vol. 37, Nº1, 2010. p. 124. 
de que el legislador ha demostrado una preocupación expresa respecto del bienestar de estos. Como se dijo anteriormente, en virtud de la Ley sobre protección de animales, estos ya no serían simplemente cosas que pueden moverse solas, sino que existe un reconocimiento a su capacidad de sufrir. Aquello motivó la incorporación del delito de maltrato animal en el artículo 291 bis del Código Penal proveniente del artículo 18 de le Ley $\mathrm{N}^{\circ} 20.380$ complementado por el artículo $36 \mathrm{~N}^{\circ} 3$ y 4 de la Ley $\mathrm{N}^{\circ}$ 21.020. Esto ha motivado un pronunciamiento doctrinal que indica que "animales y humanos son similares en su sufrimiento y dolor como seres 'sintientes', debiendo aplicarse el principio de la consideración por igual. Esto significa que deberíamos garantizar a los animales el derecho a no ser usados exclusivamente como un medio para un fin de otro, o el derecho a no ser tratados como cosas, evitando su sufrimiento y dolor, y procurando asegurar su bienestar" ${ }^{14}$. Esta postura ha sido reconocida por la jurisprudencia nacional. En un caso de maltrato animal, el Segundo Tribunal de Juicio Oral en lo Penal de Santiago, manifestó que el legislador "ha adoptado parte de lo que postula la doctrina y el derecho internacional contemporáneos, en cuanto establecen derechos para animales no humanos, los que si bien son irracionales (entendiendo la racionalidad como la capacidad de percibir, y por ello pensar acerca de las razones para nuestras creencias y acciones), con seguridad son seres animados y sintientes, acepción esta última proveniente de la capacidad de sentir, esto es, de experimentar sensaciones producidas por causas externas o internas, o experimentar una impresión, placer o dolor corporal" ${ }^{15}$. Sin embargo, existe doctrina que indica que la incorporación del delito contemplado en el artículo 291 bis del Código Penal no cambia sustancialmente el régimen jurídico de los animales. En esa línea se ha manifestado que "la tipificación así plasmada no ha desahuciado, en lo más mínimo, el compromiso regulativo con la categorización jurídica de los animales no humanos como objetos de propiedad ${ }^{16}$, esto es, como cosas, así como este último estatus

14 CHIBLE VILLADANGOS, María José: "Introducción al Derecho Animal. Elementos y perspectivas en el desarrollo de una nueva área del Derecho". En: Revista Ius et Praxis, Año 22, N², 2016. p. 398.

15 Ministerio Público contra Julio Andrés Rojas Carrasco (Segundo Tribunal de Juicio Oral en lo Penal de Santiago, 26 de febrero de 2020, Rit $\left.N^{\circ} 314-2019\right)$.

16 Sobre el debate de los animales como objetos de propiedad ver más en FRANCIONE, Gary L.: Animals as persons: Essays on the abolition of animal exploitation. Columbia University Press, New York, 2008; GARNER, Robert: "Political ideology and the legal status of animals". En: Animal Law Review, Vol. 8, 2002. pp. 77-91; MICHEL, M., KAYASSEH, E.: "The legal situation of animals in Switzerland: Two steps forward, 
-líricamente especificado como el de cosas muebles 'semovientes'- les es atribuido por el art. 567 del Código Civil" ${ }^{\prime 17}$.

Pese a que es verdad que la rigidez del Código Civil no se ve modificada por las demás normas expresadas, es a toda luz evidente que los animales tienen un estatus superior al del resto de los muebles inanimados. Esta última afirmación también encuentra asidero en la jurisprudencia nacional. En audiencia de juicio oral simplificado ante el Juzgado de Garantía de San Bernardo, el juez indicó que "se tipificó como delito todos los actos de maltrato o crueldad en contra de los animales, es decir, se les dotó de un estatuto privilegiado respecto de las demás cosas muebles por su cercanía con la vida familiar de las personas", así mismo el juez expresó que "a los animales siendo cosas muebles, se les elevó a una categoría especial, pues se les reconoció su condición de ser aptos de protección jurídica única por sobre las demás cosas muebles, independiente de si los animales tienen o no propietarios, pues se protege a los animales y no la propiedad que tenga una persona sobre esa cosa mueble semoviente"18.

En suma, las mascotas son animales y como tales son cosas. Las mascotas a su vez, solo pueden ser animales domésticos. Y dentro de la clasificación de las cosas, son bienes, ya que puede ejercerse el dominio sobre ellos, cualquiera sea su clasificación. Sin embargo, la ley, la doctrina

one step back - many steps to go". En: Journal of Animal Law, Vol. 7, 2011. pp. 1-42; SUNSTEIN, Cass R.: "The rights of animals". En: The University of Chicago Law Review, Vol. 70, 2003. pp. 387-401.

17 MAÑALICH RAFFO, Juan Pablo: "Animalidad y subjetividad. Los animales (no humanos) como sujetos-de-derecho". En: Revista de Derecho (Valdivia), Vol. XXXI, $\mathrm{N}^{\circ} 2,2018$. p. 335.

18 Ministerio Público contra Joaquín Gastón Maluenda Quezada (Juzgado de Garantía de San Bernardo, 20 de marzo de 2013, Rit No 8023-2011). Si bien esta sentencia manifiesta que el delito de maltrato animal protege a los animales y no a la propiedad que tenga una persona sobre ellos, la Corte Suprema parece tener una visión distinta. Esta última, conociendo de un recurso de nulidad interpuesto en contra de una decisión del Tribunal de Garantía de Los Ángeles, manifestó que "Si bien es cierto, puede considerarse que se ha avanzado mucho en la protección legal de los animales y fundamentalmente, en el amparo de aquellos, no se ha llegado a considerar que tengan calidad de víctimas propiamente tales de un hecho delictivo por no ser personas y siguen siendo objeto de dominio de un ser humano que, en calidad de propietario de aquéllos, es quien puede ser considerado la víctima" en Ministerio Público contra Ruperto Héctor Villamán Cáceres (Corte Suprema, 19 de octubre de 2011, Rit N ${ }^{\circ}$ 7880-2011). Aquella jurisprudencia parece poner en entredicho que los animales puedan ser víctimas directas del delito de maltrato animal con independencia de los humanos que ejerzan o no el derecho real de dominio sobre ellos. Sin embargo, la resolución de este problema excede los propósitos de este trabajo. 
contemporánea y la jurisprudencia nacional, han dotado a los animales, y por tanto a las mascotas, de un estatuto privilegiado por sobre las demás cosas muebles, elevándolos así a una categoría especial de cosa.

\section{PATRIMONIALIDAD DE LAS MASCOTAS}

Las mascotas son cosas, son bienes, y son seres sintientes, no cabe duda. Sin embargo, lo que amerita ciertas dudas es si estas cosas muebles semovientes sintientes pueden ser apreciables pecuniariamente. Peñailillo ha expresado que "Se ha sostenido que una valoración patrimonial, en el sentido de apreciación económica, pecuniaria, es indispensable en la noción jurídica de cosa, lo que justificaría las relaciones jurídicas privadas sobre ellas; pero se ha refutado enfáticamente la exigencia, extendiéndose el concepto a entidades como el nombre, el domicilio, las cuales, teniendo naturaleza extrapatrimonial, son generalmente aceptadas como objeto de relaciones jurídicas" ${ }^{\prime 9}$. Por tanto, pueden existir cosas de naturaleza extrapatrimonial, pero ¿Podrán existir bienes de naturaleza extrapatrimonial? $\mathrm{O}$ en otros términos ¿Pueden existir cosas apropiables que tengan naturaleza extrapatrimonial?

La respuesta parece entregarla el mismo Código. A modo de ejemplo puede recurrirse a dos normas. El artículo 393 sobre la administración de tutores y curadores de los bienes del pupilo y el artículo 659 sobre el modo de adquirir accesión. El primero de ellos establece que "No será lícito al tutor o curador, sin previo decreto judicial, enajenar los bienes raíces del pupilo, ni gravarlos con hipoteca, censo o servidumbre, ni enajenar o empeñar los muebles preciosos o que tengan valor de afección; ni podrá el juez autorizar esos actos, sino por causa de utilidad o necesidad manifiesta". De este artículo se desprende indudablemente la existencia de bienes muebles con valor de afección, los cuales el tutor o curador no puede enajenar ni empeñar sino autorizado por el juez y en caso de necesidad manifiesta. El artículo 659 inciso $1^{\circ}$ expresa respecto de la accesión que "Si de las dos cosas unidas, la una es de mucho más estimación que la otra, la primera se mirará como lo principal y la segunda como lo accesorio", por su parte el inciso $2^{\circ}$ manifiesta que "Se mirará como de más estimación la cosa que tuviere para su dueño un gran valor de afección". Por lo tanto, la estimación no es pecuniaria ni económica, es de afección, es decir, extrapatrimonial. Cabe destacar que es posible valorar pecuniariamente un

19 PEÑAILILLO, cit. p. 14. 
bien con valor de afección, por algo el artículo 393, con autorización del juez, permite enajenarlo. Lo destacable de aquella norma, es que parece indicar que los bienes con valor de afección son de más difícil valoración pecuniaria, y tienen para el pupilo más valor del que tutor puede concebir o imaginar, por eso le está vedado a él enajenarlos. En lo que respecta a mascotas probablemente muchos dueños se vean moralmente impedidos de ponerle precio. Existe un interés moral en ellos que impide dicha valoración de forma cómoda, aunque no sea imposible realizarla, de manera que perfectamente pueden ser considerados bienes con valor de afección para algunos dueños.

Como indica Stitchkin "Estos valores o intereses no pecuniarios son amparados por el ordenamiento jurídico, pero falta la formulación general o sistemática que configure ese campo de intereses consustancial a la personalidad. Tales intereses están en el patrimonio de la persona; el ordenamiento jurídico los contempla, los consagra, les reconoce trascendencia jurídica. Pero es tímido para expresar la fórmula general. Es curiosa esta timidez. Este contrapunto que se advierte entre la actitud severa del derecho que aparentemente no quiere entrar en el terreno de los valores subjetivos, morales o ideales, y la actitud general de la sociedad que aumenta cada día su preocupación por tales intereses y valores" ${ }^{20}$. Los bienes envueltos o ligados a estos valores de afección podríamos denominarlos bienes extrapatrimoniales, y a este respecto Stitchkin ha expresado que "El afecto es un bien jurídico y nuestro Código Civil lo contempla reiteradamente para someterlo a su protección. Ya vimos el caso de la accesión de mueble a mueble por adjunción y como se califica de cosa principal aquella que tiene para su dueño un gran valor de afección. Y hemos visto también que el tutor o curador no puede enajenar libremente los bienes muebles del pupilo que tuvieren para éste un valor de afección" ${ }^{21}$.

Las mascotas parecen ser de este tipo de bienes para su dueño. Al ser animales de compañía y seguridad, es posible desarrollar afecto hacia ellos. Estos afectos han sido reconocidos por la jurisprudencia. La Corte de Apelaciones de Temuco, conociendo de un recurso de apelación en un caso de maltrato animal manifestó que "el legislador ha recogido el consenso social que reconoce la importancia y función social de los animales en la vida humana en diversos ámbitos, no sólo el económico, sino que también

20 STITCHKIN BRANOVER, David: "Los bienes extrapatrimoniales". En: Revista de Derecho Universidad de Concepción, N 115, Año XXIX, 1961. p. 19.

21 Ibídem, p. 25. 
el afectivo o de otras índoles" ${ }^{\prime 2}$. De manera tal que, dentro de lo que se ha descrito anteriormente, serían bienes con valor de afección, y aquello complica sobremanera su avaluación pecuniaria o económica. Sin embargo, debe insistirse en que, como cosa y bien, es posible valorar pecuniaria y económicamente a la mascota de acuerdo a la valoración de estas en el mercado, aunque dicha actividad resulte incómoda para algunos dueños.

Considerando aquello, es del todo sensato concluir que, al ser bienes con valor de afección, un daño en ellos o su pérdida producto de un ataque, produzca un daño moral en su dueño. Desde ese punto de vista, el fallo expuesto declara correctamente el daño moral de la dueña producto del daño sufrido por su mascota Olivia.

Con todo, estos serían bienes con valor de afección para su dueño, no para terceros. Así por ejemplo, la empresa dueña de las mascotas cuyo giro comercial es la venta de estas, no tiene impedimento alguno para ponerle precio a las mascotas, y para ella, estos no son bienes con valor de afección. Por tanto, la mascota solo genera afección en aquella persona que lo tiene para su compañía y cuidado. O dicho en otros términos, para la empresa los animales que tiene a la venta no son jurídicamente mascotas, son solo animales. Serán mascotas en la medida que cumplan con la finalidad de proveer compañía o seguridad.

\section{EL DUEÑO ¿VÍCTIMA DIRECTA O POR REPERCUSIÓN?}

El Ministro de Fuero indemnizó el daño moral de la dueña de Olivia en una suma ascendente a un millón de pesos. Sin lugar a dudas, el Ministro consideró que la dueña estaba demandando como víctima directa del daño. Sin embargo, manifestó que la indemnización de perjuicios se solicitó derivada "de la angustia y conflictos psicológicos ocasionados por la acción que su mascota generó tanto en Olivia como en su dueña y su núcleo familiar. Para puntualizar lo anterior, pide tener presente que, tal como se puede imaginar, el hecho de que una mascota que los ha acompañado durante más de 6 años sea brutalmente atacada por un animal fiero, es un hecho traumático, al punto que ha ocasionado en la mascota un episodio de afectación general, pero, además, obviamente en el núcleo familiar de sus dueño, en el entendido que se encuentran limitados en la actualidad a pasearla (tiene pánico de salir a la calle y sociabilizar con otros animales),

22 Ministerio Público contra Osvaldo Ernesto Cayulao Soto (Corte de Apelaciones de Temuco, 04 de diciembre de 2018, Rol N 1009-2018). 
y problemas conductuales derivados del ataque, todo, como consecuencia de la irresponsabilidad de la demandada". En esa misma línea, el Ministro de Fuero expresa que "la perrita 'Olivia' de propiedad de la demandante, es una perrita inserta en un grupo familiar humano, como una mascota querida, tratada no como una cosa sino como un miembro importante del entorno familiar, bien cuidada en cuanto a facilitarle frecuentes paseos y de aspecto alegre, lo que cambió luego del ataque". De aquí, podría surgir la idea de que en realidad, la demandante está demandando también el daño moral de Olivia y que sería esta la víctima directa del daño, y que por ende, la dueña sería la victima por repercusión.

Si bien la demandante indica que Olivia sufrió daño corporal y psicológico, los que, como se verá, en nuestra doctrina corresponden a daños morales o extrapatrimoniales, el Ministro parece razonar que dichas alegaciones tan solo tienen relevancia para efectos de evaluar el daño moral de la dueña, puesto que los argumentos utilizados por ella para concederlo se centran únicamente en el daño padecido por esta. De manera tal que el Ministro no razonó que la víctima directa era Olivia y que la dueña era víctima por repercusión, sino que la dueña era la victima directa. Esta es la decisión jurídicamente correcta por dos motivos.

Primero, los bienes, y por ende las mascotas, no tienen patrimonio. Todas las teorías sobre el patrimonio que existen, apuntan a que el patrimonio se encuentra ligado a las personas. Se ha manifestado que "Castán Tobeñas resume las teorías relativas al patrimonio y dice a manera de introducción: 'No hay unanimidad en la apreciación de las acepciones del concepto, de la naturaleza jurídica, del contenido ni de las clases del patrimonio', si está compuesto exclusivamente por el activo o también por el pasivo, si constituye una unidad distinta de sus elementos (universitas iuris) o simplemente una pluralidad de bienes o derechos; si el concepto de patrimonio es o no inseparable de la persona, y consiguientemente si pueden existir patrimonios sin persona y si puede una misma persona tener diversos patrimonios, o sea, patrimonios separados" ${ }^{23}$. Si bien es cierto que no existe unanimidad en las acepciones del concepto de patrimonio, de la cita parece inferirse que este se encuentra ligado al concepto de persona bajo su definición legal del artículo 55 del Código Civil. Ahora bien, la persona puede ser natural o jurídica ${ }^{24}$. Las mascotas no están contempladas

23 NIÑO TEJEDA, Eduardo: "Esquema sobre el patrimonio". En: Revista de Derecho de la Universidad Católica de Valparaíso, $\mathrm{N}^{\circ} 15,1993$. p. 153.

24 Ibídem, p. 163. 
dentro de este concepto. Si es cierto que el patrimonio es un conjunto de derechos $^{25}$, o un conjunto de relaciones jurídicas apreciables en dinero ${ }^{26}$, y las mascotas no lo tienen, entonces no tienen derecho a indemnización de ningún tipo, ni siquiera moral, ya que si bien el daño moral comprende indemnizar un daño irreparable y no patrimonial, su propia existencia implica apreciarlo en dinero, y ese dinero necesaria e indudablemente debe estar afecto a un patrimonio.

Segundo y respecto al daño moral, Barros ha manifestado que "Alessandri, siguiendo a los hermanos Mazeaud, lo definía como "el dolor, pesar o molestia que sufre una persona en su sensibilidad física o en sus sentimientos, creencias o afectos" ${ }^{27}$ y Carmen Domínguez ha dicho que el daño moral se refiere "más bien a una categoría de perjuicios que precisamente tienen en común su carácter no patrimonial, esto es que importan un atentado a la persona en sus derechos o intereses no patrimoniales tales como su salud, su estética, esfera de intimidad, honor, libertad, sentimientos de afección, etc." ${ }^{28}$. De lo expresado por los autores, el daño moral tan solo puede ser sufrido por personas, y por tanto, se debe destacar con insistencia que las mascotas son cosas y bienes, por tanto, no sufren daño moral. Los que sufren daño moral son las personas, ya sean naturales o jurídicas, pero no las cosas. El fallo comentado también lo aclara al manifestar que "en cuanto al Daño Moral, cabe señalar que aquel consiste en el dolor, la angustia la aflicción física y espiritual, y en general, los padecimientos infringidos a la víctima por el evento dañoso. En otras palabras, es aquel perjuicio sufrido a la psiquis de una persona". Por ende, las mascotas no pueden sufrir daño moral y no pueden ser indemnizadas como víctimas directas, ya que no son personas.

Con todo debe manifestarse a su vez, que la definición de daño moral ha sufrido importantes cambios a lo largo de su historia. La primera sentencia que reconoce esta partida de daños en Chile data de $1922^{29}$ y desde entonces

25 STITCHKIN, cit., p. 4.

26 NIÑO, cit., p. 154.

27 BARROS BOURIE, Enrique: Tratado de responsabilidad extracontractual. Editorial Jurídica de Chile, Santiago, 2006. p. 231

28 DOMÍNGUEZ HIDALGO, Carmen: "Hacia una uniformidad y transparencia de la fijación del quantum indemnizatorio por daño moral”. En: Corral Talciani, Hernán y Rodríguez Pinto, María Sara (Coord.): Estudios de Derecho Civil II. Santiago, Legal Publishing, 2006. p. 289.

29 CÁRDENAS, H, GONZÁLEZ, P: "Notas sobre el daño moral: Concepto, prueba y avaluación en una reciente sentencia de la Corte de Apelaciones de Santiago". En: Revista de Derecho Universidad Católica del Norte, Año 12, º2, 2005. p. 
su definición ha tenido un notable avance en su desarrollo. Díez-Picazo ha manifestado que "hay un concepto estricto de daño moral que arranca de la vieja idea de pretium doloris y que se ha definido como dolor, sufrimiento, padecimiento psíquico o físico injustamente ocasionado" ${ }_{30}$, pero indica así mismo, que existe doctrina que asocia el daño moral a aquel que deriva de ataques a la integridad física, al que denominan daño corporal, y que dentro de aquel concepto incluyen i) Los sufrimientos morales y psíquicos, que comprenden las mismas ideas que la vieja idea pretium doloris; ii) El perjuicio estético (prix de la beauté, pretium pulchritudinis); iii) El denominado «perjuicio sexual», que comprende la imposibilidad total o parcial para la víctima de mantener relaciones sexuales o de procrear; y iv) El daño a la que podríamos denominar vida de relación (préjudice d'agrément) $)^{31}$. Por ende, los daños extrapatrimoniales pueden contemplar daños diversos entre sí, los cuales son difíciles de categorizar. Por ello, existe doctrina que propone superar la idea reduccionista que identifica al daño moral tan solo con el pretium doloris ${ }^{32}$, "que el concepto de daño moral es más amplio y que más bien la categoría pretium doloris constituye la especie del género "daño extrapatrimonial"' ${ }^{3}$. En virtud de dicha afirmación se ha dicho "que la expresión 'daño moral' se relaciona con un concepto jurídico indeterminado mucho más amplio hoy que el simple pretium doloris, que no es sino una especie más de daño moral" ${ }^{34} \mathrm{y}$ que "Por lo tanto, no todo daño extrapatrimonial es pretium doloris, aunque todo pretium doloris sí es un daño extrapatrimonial, hay una relación más bien de género a especie" ${ }_{35}$. Conclusivamente se ha manifestado que "Hoy el daño extrapatrimonial protege más allá del pretium doloris que es solo una especie del mismo. Así, si la víctima ha sufrido un daño corporal o un daño a la dignidad humana, a la libertad o a otros derechos de la personalidad, debe ser indemnizada por daño moral" ${ }^{3_{6}}$.

30 DIEZ-PICAZO Y PONCE DE LEÓN, Luis: Derecho de Daños. Civitas Ediciones, S.L., Madrid, 1999. p. 326.

31 Ibídem, p. 327.

32 BARRIENTOS ZAMORANO, Marcelo: "Del daño moral al daño extrapatrimonial: La superación del pretium doloris”. En: Revista Chilena de Derecho, Vol. 35, №1, 2008. p. 85.

33 GONZÁlEZ CAZORLA, Fabián A.: "Delimitación del daño moral a través de consideraciones de justicia distributiva". En: Revista de Derecho (Concepción), Vol. 85, $\mathrm{N}^{\circ}$ 242, 2017. pp. 195-196.

34 BARRIENTOS, cit., p. 90.

35 Ibídem

36 Ibídem, p. 85. 
Por tanto, si bien es cierto que de acuerdo a las definiciones clásicas, el daño moral tan solo puede ser sufrido por personas, también es cierto que de la evolución del concepto mismo de daño moral se ha arribado al concepto de daño corporal, el cual de forma evidente puede ser sufrido por animales. El legislador ha demostrado ser perfectamente consciente de aquello al manifestar que los animales merecen un trato adecuado y sobre los que cabe evitar provocarles sufrimientos innecesarios, lo que se ha visto reforzado por la jurisprudencia. Esta última ha manifestado que los animales pueden "experimentar una impresión, placer o dolor corporal", desde donde se evidencia una notoria aproximación conceptual entre el reconocimiento de animales y mascotas como seres sintientes y el daño corporal como categoría de daño moral. Con todo, los avances en torno al daño moral no parecen haber llegado al punto de concederles esta partida indemnizatoria a los animales, sin embargo, es un avance notable puesto que los aproxima notoriamente a ser indemnizados como víctimas directas. Por el momento, no quedaría sino afirmar que los animales y mascotas, en estricto rigor, sufren daño corporal, pero este no podría ser entendido como un daño moral o extrapatrimonial indemnizable para ellos. No resultan ser ellos los indemnizados como víctimas directas, sino el ser humano que ejerce dominio sobre ellos, dentro de cuyo patrimonio estos se encuentran.

Lo anterior puede resumirse en virtud de lo manifestado por el profesor Agustín Squella, quien expresa que "todo hombre es persona y a toda persona, cualquiera sea su edad estado o condición, se le reconoce como sujeto de derecho, lo cual equivale a decir que toda persona es apta para tener derechos y obligaciones jurídicas" ${ }^{37}$, en esa misma línea, el autor clasifica a los sujetos jurídicos entre sujetos individuales y colectivos. Los individuales son las personas humanas que se identifican con el concepto de persona natural y los colectivos son "personas ficticias capaces de ejercer derechos y contraer obligaciones y de ser representadas judicial y extrajudicialmente" ${ }_{38}$. De acuerdo a Squella, "Tanto los sujetos jurídicos individuales como los de carácter colectivo participan de determinados atributos, a saber, la capacidad de goce, nacionalidad, el nombre, el patrimonio y el domicilio" ${ }^{39}$. Si los sujetos de derechos individuales son solo personas humanas y los sujetos colectivos están compuestos por la voluntad

37 SQUELLA NARDUCCI, Agustín: Introducción al derecho. $2^{\mathrm{a}}$ ed. Actualizada y ampliada. Editorial Jurídica de Chile, Santiago, 2011. p. 179.

38 Ibídem, p. 97.

39 Ibídem. 
de dos o más sujetos individuales ${ }^{40}$ humanos, las mascotas no son sujetos de derechos, no tienen derecho a ser indemnizados y no tienen patrimonio al que dicho activo pueda dirigirse. Conclusivamente el autor manifiesta que "el derecho es un orden normativo que regula la conducta humana y que, al hacerlo, reconoce o atribuye derechos, en el sentido subjetivo de esta palabra, así como impone también deberes y obligaciones, únicamente a individuos de la especie humana, y no a animales no humanos, vegetales $\mathrm{y}$ objetos inanimados, y del hecho de que animales, especies vegetales y ciertos objetos inanimados se encuentren protegidos jurídicamente no se puede inferir que ellos gocen de derechos al modo como sí los tienen las personas o individuos de la especie humana"41.

En virtud de lo anterior es del todo sensato que el Ministro de Fuero haya considerado que la alegación del daño corporal y psicológico de Olivia tan solo tenía relevancia para efectos de analizar el daño moral de la dueña, no de la perra propiamente tal. En otros términos, el daño de la perra, en sí mismo, es irrelevante, tan solo tiene importancia para efectos de evaluar la existencia del daño moral de su dueña.

En el caso en comento, la demandante hace referencia al daño corporal y psicológico de Olivia. Aquello puede dar la apariencia de que la dueña demandó el daño moral propio de Olivia como víctima directa y el suyo propio como víctima por rebote ${ }^{42}$. Esta apariencia permitió al Ministro utilizar los daños corporales y psicológicos de Olivia para conceder el daño moral de la dueña. El Ministro de Fuero declaró que Olivia no era tratada como una cosa, sino como un miembro de la familia, que era una "mascota querida", y que su aspecto alegre cambió luego del ataque. De aquello puede inferirse cuatro cosas. Primero, del hecho de que la mascota sea tratada como miembro de la familia se infiere que el daño en ella produce daño moral a su dueña. Segundo, al ser Olivia una mascota querida, no puede sino inferirse el reconocimiento jurisprudencial expreso de que las mascotas son bienes con valor de afección. Tercero, el daño sufrido por la dueña en su patrimonio es más bien de carácter extrapatrimonial, al ver afectada una cosa con valor de afección. Cuarto y final, si bien se ha

40 Ibídem.

41 Ibídem, p.199.

42 Ver más sobre las víctimas por rebote en ELORRIAGA DE BONIS, Fabián: "Del daño por repercusión o rebote”. En: Revista Chilena de Derecho, Vol. 26, №2, 1999. pp. 369398; ELORRIAGA DE BONIS, Fabián: "Novedades judiciales en torno al daño moral por repercusión”. En: Corral Talciani, Hernán y Rodríguez Pinto, María Sara (Coord.): Estudios de Derecho Civil II. Santiago, Legal Publishing, 2006. pp. 297-322. 
expresado con insistencia que las mascotas no pueden ser indemnizadas, no es menos cierto que el Ministro de Fuero de la Corte de Apelaciones reconoció que Olivia sufrió un daño corporal producto del ataque y también uno psicológico al abandonar su aspecto alegre, y dichos daños, al menos en humanos, corresponden a daño moral, evidenciándose una relación conceptual entre el daño corporal, que puede ser sufrido por animales, y el daño moral, el cual aún parece no ser indemnizable directamente para ellos.

En suma, el fallo es particularmente interesante al tratar el daño moral de la dueña de la mascota, ya que recurre al daño sufrido por esta para examinar la existencia y cuantificación del daño moral de la primera, declarando expresamente que la mascota no era tratada como una cosa, sino como un miembro de la familia y que aquello, debe ser tenido en cuenta al momento de evaluar el daño moral de la dueña.

\section{CONCLUSIONES}

Este trabajo versó sobre el daño moral indemnizable sufrido por el dueño de una mascota frente a un ataque en ella. Se inició analizando el régimen jurídico de animales y mascotas concluyendo que las leyes de protección animal y tenencia responsable de mascotas no modifican el régimen jurídico de las mascotas, de manera tal que estas son cosas, y no tan solo cosas, sino que también son bienes, por ser susceptibles de apropiación mediante el derecho real de dominio.

Sin embargo, pese a ser cosas y bienes, se analizó que las mascotas eran seres sintientes y por tanto, se encontraban en una categoría especial privilegiada por sobre los demás bienes muebles semovientes. Estas particulares características los volvían bienes con valor de afección, es decir, al analizar su carácter patrimonial se concluyó que, si bien es posible valorizarlos económicamente, existían ciertos intereses morales en ellos, que dificultaban dicha actividad, lo que motivó recurrir al concepto de bienes extrapatrimoniales expuesto por David Stitchkin. Ahora bien, de acuerdo al autor, la existencia de este tipo de bienes y de este tipo de intereses, implicaba aceptar que el patrimonio se encuentra compuesto por intereses y derechos que no necesariamente pueden ser avaluables pecuniariamente, y si bien las mascotas son avaluables, se encuentran envueltas o ligadas a intereses morales para sus dueños.

Atendido a que las mascotas son bienes con valor de afección y que por tanto contemplan intereses no estrictamente pecuniarios, es sensato 
concluir que un daño en ellos produce aflicción psicológica en su dueño correspondiente a un daño moral, y aquello fue declarado expresamente por un Ministro de Fuero de la Corte de Apelaciones de Santiago en el caso aquí expuesto.

Junto con aquello, el Ministro declaró que la mascota no era tratada como cosa, y que junto con el daño corporal producido por la mordida del otro perro, la mascota de la demandante cambió su comportamiento, dejando de ser alegre. Aquello podría dar la apariencia de que la mascota también sufrió un daño moral, y que la dueña de la mascota sería en realidad, una víctima por repercusión. El Ministro de Fuero declaró lo contrario, que el daño sufrido por la mascota tuvo relevancia tan solo para efectos de evaluar el daño de su dueña y que era esta la victima directa del daño. Aquello es jurídicamente correcto toda vez que las mascotas no tienen patrimonio y no pueden sufrir un daño moral, al menos no uno indemnizable, ya que estas dos cosas están reservadas solo a personas, naturales o jurídicas, no a las cosas. Con todo, su reconocimiento como seres sintientes, y los avances en el concepto de daño moral y daño corporal, podrían llegar a significar una aproximación conceptual notable a un eventual reconocimiento como seres sujetos a indemnización de este tipo de daños de forma directa.

Finalmente, pese a lo anterior, si bien las mascotas son cosas bien valoradas socialmente, aun no puede declararse que puedan sufrir un daño moral indemnizable. Actualmente, siempre será su dueño la víctima directa del daño, puesto que las mascotas forman parte de su patrimonio, de manera tal que, por el momento, las mascotas tan solo pueden ser consideradas bienes con valor de afección, especialmente protegidos y privilegiados por sobre los demás bienes.

\section{BIBLIOGRAFÍA}

ALESSANDRI RODRÍGUEZ, Arturo: De los bienes. Editorial Zamorano y Caperan, Santiago, 1937.

BARROS BOURIE, Enrique: Tratado de responsabilidad extracontractual. Editorial Jurídica de Chile, Santiago, 2006.

BOBBIO, Norberto: Teoría general del derecho. $2^{\mathrm{a}}$ ed. Editorial Temis, Bogotá, 2002. 
CÁRDENAS, H, GONZÁLEZ, P: "Notas sobre el daño moral: Concepto, prueba y avaluación en una reciente sentencia de la Corte de Apelaciones de Santiago". En: Revista de Derecho Universidad Católica del Norte, Año 12, №2, 2005.

CHIBLE VILLADANGOS, María José: “Introducción al Derecho Animal. Elementos y perspectivas en el desarrollo de una nueva área del Derecho". En: Revista Ius et Praxis, Año 22, Nº 2, 2016.

CORRAL TALCIANI, Hernán: Lecciones de responsabilidad civil

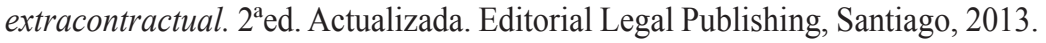

DÍAZ VIDELA, Marcos: "El miembro no humano de la familia: las mascotas a través del ciclo vital familiar". En: Revista Ciencia Animal, $\mathrm{N}^{\circ}$ 9, 2015.

DIEZ-PICAZO Y PONCE DE LEÓN, Luis: Derecho de Daños. Civitas Ediciones, S.L., Madrid, 1999.

DOMÍNGUEZ HIDALGO, Carmen: "Hacia una uniformidad y transparencia de la fijación del quantum indemnizatorio por daño moral". En: Corral Talciani, Hernán y Rodríguez Pinto, María Sara (Coord.): Estudios de Derecho Civil II. Santiago, Legal Publishing, 2006.

ELORRIAGA DE BONIS, Fabián: "Del daño por repercusión o rebote". En: Revista Chilena de Derecho, Vol. 26, N², 1999.

ELORRIAGA DE BONIS, Fabián: "Novedades judiciales en torno al daño moral por repercusión" En: Corral Talciani, Hernán y Rodríguez Pinto, María Sara (Coord.): Estudios de Derecho Civil II. Santiago, Legal Publishing, 2006.

FRANCIONE, Gary L.: Animals as persons: Essays on the abolition of animal exploitation. Columbia University Press, New York, 2008.

GARNER, Robert: "Political ideology and the legal status of animals". En: Animal Law Review, Vol. 8, 2002.

GONZÁLEZ CAZORLA, Fabián A.: "Delimitación del daño moral a través de consideraciones de justicia distributiva". En: Revista de Derecho (Concepción), Vol. 85, № 242, 2017.

JOFRÉ M, Leonor: "Visita terapéutica de mascotas en hospitales". En: Revista Chilena de Infectología, Vol. 22, 2005. 
LÓPEZ, J, PEÑA, A, ABARCA, K: "Tenencia de mascotas en pacientes inmunocomprometidos: actualización y consideraciones veterinarias $\mathrm{y}$ médicas”. En: Revista Chilena de Infectología, Vol. 30, №3, 2013.

MAÑALICH RAFFO, Juan Pablo: "Animalidad y subjetividad. Los animales (no humanos) como sujetos-de-derecho". En: Revista de Derecho (Valdivia), Vol. XXXI, N², 2018.

MICHEL, M., KAYASSEH, E.: "The legal situation of animals in Switzerland: Two steps forward, one step back - many steps to go". En: Journal of Animal Law, Vol. 7, 2011.

NINO, Carlos Santiago: Introducción al análisis del derecho. $2^{\mathrm{a}}$ ed. Ampliada y revisada. Editorial Astrea de Alfredo y Ricardo Depalma, Buenos Aires, 2003.

NIÑO TEJEDA, Eduardo: "Esquema sobre el patrimonio". En: Revista de Derecho de la Universidad Católica de Valparaíso, № 15, 1993.

PEÑAILILLO ARÉVALO, Daniel: Los bienes. La propiedad y otros derechos reales. $1^{\mathrm{a}}$ ed. Editorial Jurídica de Chile, Santiago, 2006.

SCHIELE, C, TOCORNAL, J: “Artículo 2329 del Código Civil. La interpretación de presunción por hechos propios existe en la jurisprudencia". En: Revista Chilena de Derecho, Vol. 37, N¹, 2010.

SQUELLA NARDUCCI, Agustín: Introducción al derecho. $2^{\mathrm{a}}$ ed. Actualizada y ampliada. Editorial Jurídica de Chile, Santiago, 2011.

STITCHKIN BRANOVER, David: "Los bienes extrapatrimoniales". En: Revista de Derecho Universidad de Concepción, N 115, Año XXIX, 1961.

SUNSTEIN, Cass R.: "The rights of animals". En: The University of Chicago Law Review, Vol. 70, 2003.

TONCOSO LARRONDE, Hernán: De los bienes. Editorial Thomson Reuters, Santiago, 2013.

\section{Jurisprudencia citada}

Ministerio Público contra Joaquín Gastón Maluenda Quezada (Juzgado de Garantía de San Bernardo, 20 de marzo de 2013, Rit N 8023-2011).

Ministerio Público contra Julio Andrés Rojas Carrasco (Segundo Tribunal de Juicio Oral en lo Penal de Santiago, 26 de febrero de 2020, Rit N 314-2019). 
Ministerio Público contra Osvaldo Ernesto Cayulao Soto (Corte de Apelaciones de Temuco, 04 de diciembre de 2018, Rol N 1009-2018).

Ministerio Público contra Ruperto Héctor Villamán Cáceres (Corte Suprema, 19 de octubre de 2011, Rit No 7880-2011).

Vivanco con Nazal (Corte de Apelaciones de Santiago, 09 de septiembre de 2019, Rol N 13-2018).

Vivanco con Nazal (Segundo Juzgado de Policía Local de Las Condes, 31 de enero de 2019, Rol No 15-347-2018). 